\title{
Exposure Response Relationship of Acute Effects of Air Pollution on Respiratory Diseases - China, 2013-2018
}

\author{
Hongtao Niu ${ }^{1,2,3,4}$; Tao $\mathrm{Yu}^{1,2,3,4,5}$; Xuexin $\mathrm{Li}^{1,2,3,4,6} ;$ Hanna $\mathrm{Wu}^{1,2,3,4,6} ;$ Meilin Yan ${ }^{7,8}$; Ruirui Duan'; Ting Yang ${ }^{1,2,3,4,4}$
}

\section{Summary \\ What is already known about this topic? \\ Short-term exposure to air pollutants has been associated with chronic obstructive pulmonary disease (COPD) and asthma, which needs continuous observation. \\ What is added by this report? \\ This study uses the longest time series data so far from 2013 to 2018 and adds additional data analysis for ozone $\left(\mathrm{O}_{3}\right)$ to existing studies. \\ What are the implications for public health practice? \\ This study suggests that air pollutants have certain acute effects on outpatient and hospital admission of patients with COPD and asthma, which can be combined with the disease diagnosis and treatment guidelines to guide clinical practice.}

Chronic obstructive pulmonary disease (COPD) and asthma are two major chronic airway diseases. Recent studies have focused on the relationship between air pollution and the development of acute exacerbations of COPD and asthma. In 2021, Liu et al. found that fine particulate matter (particles with aerodynamic diameter $\left.\leq 2.5 \mu \mathrm{m} ; \mathrm{PM}_{2.5}\right)$ and nitrogen dioxide $\left(\mathrm{NO}_{2}\right)$ increased the risk of COPD and asthma (1). Doiron et al. found that $\mathrm{PM}_{2.5}$, particles with aerodynamic diameter $\leq 10 \mu \mathrm{m}\left(\mathrm{PM}_{10}\right)$ and $\mathrm{NO}_{2}$ significantly enhanced the morbidity of COPD (2). However, in 2014, a study found that neither $\mathrm{NO}_{2}$ nor PM levels were associated with COPD morbidity (3). It can be concluded that there is no clear conclusion whether short-term exposure to air pollution increases the health risk of COPD and asthma patients. Meanwhile, in China, the available studies about air pollution are based on a three-year time series of data from 2013-2015 (4), which may not reflect the health effects of recent air quality improvement initiatives. Therefore, we analyzed daily outpatient and hospitalization data from the China CDC Disease Surveillance Point System (DSPs) from
January 1, 2013 to December 31, 2018 to explore the impact of short-term exposure to air pollution on the acute effects of patients with COPD and asthma.

This study collected inpatient and outpatient data for respiratory diseases, concentration of each air pollutant, as well as temperature and relative humidity data from January 1, 2013 to December 31, 2018 in 16 hospitals in China in 5 cities $(6$ districts and counties). We used the International Classification of Diseases Revision 10 (ICD-10) codes J40-J44 for COPD visits and codes J45-J46 for asthma. Relevant air pollution data was obtained from the National Urban Air Quality Real-Time Release Platform, and temperature and relative humidity was obtained from the National Meteorological Information Center.

Pollutant concentrations were aggregated to daily means [carbon monoxide $(\mathrm{CO})$, sulfur dioxides $\left(\mathrm{SO}_{2}\right)$, $\mathrm{NO}_{2}, \mathrm{PM}_{2.5}$, and $\mathrm{PM}_{10}$ ] and daily maximum 8-hour means $\left(\mathrm{O}_{3}\right)$.

We used a time-stratified case-crossover design to analyze the associations between air pollution and hospital admissions for respiratory diseases. A time stratum was defined as a combination of year, month, and day-of-week levels. This design allows for the adjustment of long-term and seasonal trends. We then fit a generalized linear model (GLM) with a Poisson distribution. Daily mean temperature and relative humidity were also controlled by the natural spline function in the model. The "stats" package in $\mathrm{R}$ software (version 4.0.2, R Foundation for Statistical Computing, Vienna, Austria) was used for analysis. Results were presented as the percentage changes and 95\% confidence intervals (CIs) in daily inpatient and outpatient rates associated with a per $10 \mu \mathrm{g} / \mathrm{m}^{3}$ increase in air pollutants $\left(\mathrm{CO}\right.$ is $\left.\mathrm{mg} / \mathrm{m}^{3}\right)$. We also assessed the single-day lag effect (from 0 to 3 ) and the cumulative lag effect $(0-1,0-2$, and $0-3)$ of air pollutants on daily outpatient and hospitalization rates.

In total, 85,961 outpatient visits and 62,381 hospital admissions were observed for COPD and asthma in 16 hospitals from 2013 to 2018.

Table 1 shows the mean pollutant concentrations, 
TABLE 1. Daily counts of hospitalizations and outpatient visit for respiratory diseases and air pollution levels in China, 2013-2018.

\begin{tabular}{lc}
\hline \multicolumn{1}{c}{ Variables } & Mean (SD) \\
\hline Outpatient visit (daily counts per county) \\
COPD & $38(18)$ \\
Asthma & $8(5)$ \\
Hospitalizations (daily counts per county) & \\
COPD & $6(4)$ \\
Asthma & $3(2)$ \\
Pollutants & \\
$\mathrm{PM}_{2.5}\left(\mu \mathrm{g} / \mathrm{m}^{3}\right)$ & $59.1(43.4)$ \\
$\mathrm{PM}_{10}\left(\mu \mathrm{g} / \mathrm{m}^{3}\right)$ & $95.9(61.9)$ \\
$\mathrm{O}_{3}\left(\mu \mathrm{g} / \mathrm{m}^{3}\right)$ & $112.8(59.3)$ \\
$\mathrm{SO}_{2}\left(\mu \mathrm{g} / \mathrm{m}^{3}\right)$ & $19.8 .2(17.2)$ \\
$\mathrm{NO}_{2}\left(\mu \mathrm{g} / \mathrm{m}^{3}\right)$ & $47.9(21.3)$ \\
$\mathrm{CO}^{3}\left(\mathrm{mg} / \mathrm{m}^{3}\right)$ & $1.1(0.7)$ \\
$\mathrm{AbbreV}^{3} \mathrm{l}$ &
\end{tabular}

Abbreviations: $\mathrm{SD}=$ standard deviation; $\mathrm{COPD}=$ chronic obstructive pulmonary disease; $\mathrm{PM}_{2.5}=$ particulate matter $\leq 2.5 \mathrm{~m}$ in diameter; $\mathrm{PM}_{10}=$ particulate matter $\leq 10 \mathrm{~m}$ in diameter; $\mathrm{SO}_{2}=$ sulfur dioxides; $\mathrm{NO}_{2}=$ nitrogen dioxide; $\mathrm{CO}=$ carbon monoxide; $\mathrm{O}_{3}=$ ozone.

and the average daily respiratory disease hospitalizations and outpatient visits in the study areas (expressed as mean and standard deviation). The average daily respiratory disease outpatient visits were approximately 38 for COPD and 8 for asthma, 6 for COPD, and 3 for asthma in daily hospital admissions.

Atmospheric pollutants had an acute effect on the risk of hospitalization for COPD (Figure 1A), and the acute effects of $\mathrm{PM}_{2.5}, \mathrm{O}_{3}$, and $\mathrm{CO}$ on the risk of hospitalization for COPD were most pronounced at lag02, with each $10 \mu \mathrm{g} / \mathrm{m}^{3}$ increase in $\mathrm{PM}_{2.5}, \mathrm{O}_{3}$, and $\mathrm{CO}$ increasing the risk of hospitalization for COPD by $1.1 \% \quad(95 \%$ CI: $\quad 0.6 \%-1.7 \%), \quad 1.7 \% \quad(95 \%$ CI. $1.3 \%-2.1 \%$ ), and $88.2 \%$ (95\% CI: $6.7 \%-232 \%$ ). However, no acute effect of air pollutants on the risk of hospitalization for asthma was seen (Figure 1B).

In patients with COPD, $\mathrm{O}_{3}$ was negatively associated with an increased risk of outpatient visits for COPD (Figure $2 \mathrm{~A}$ ), and $\mathrm{NO}_{2}$ was positively associated with increased risk of outpatient visits for COPD, most strongly at lag02, with each $10 \mu \mathrm{g} / \mathrm{m}^{3}$ increase in $\mathrm{NO}_{2}$ associated with a $2.4 \%$ (95\% CI: $0.4 \%, 4.4 \%$ ) increase in risk of outpatient visits for patients with COPD.

Among asthma patients, $\mathrm{PM}_{2.5}$ and $\mathrm{PM}_{10}$ were negatively associated with the risk of outpatient visits (Figure 2B), with the strongest at lag1, where each $10 \mu \mathrm{g} / \mathrm{m}^{3}$ increase in $\mathrm{PM}_{2.5}$ and $\mathrm{PM}_{10}$ was associated with a $0.6 \%(95 \%$ CI: $-0.9 \%,-0.2 \%)$ and $0.4 \%(95 \%$ CI: $-0.7 \%,-0.2 \%)$ decrease in the risk of outpatient visits for asthma patients, respectively. $\mathrm{O}_{3}, \mathrm{SO}_{2}$, and $\mathrm{NO}_{2}$ were positively associated with increased risk of outpatient asthma visits and were strongest at lag02, with each $10 \mu \mathrm{g} / \mathrm{m}^{3}$ increase in $\mathrm{O}_{3}$ and $\mathrm{NO}_{2}$ increasing the risk of outpatient asthma visits by $0.9 \%$ (95\% CI: $0.5 \%, 1.3 \%$ ) and $2.9 \%$ (95\% CI: $2 \%$, $3.8 \%$ ), respectively. The acute effect of $\mathrm{SO}_{2}$ on outpatient asthma visits was strongest at lag2, with each $10 \mu \mathrm{g} / \mathrm{m}^{3}$ increase in $\mathrm{SO}_{2}$ increasing the risk of outpatient visits for asthma patients by $1.1 \%(95 \% \mathrm{CI}$ : $0.1 \%, 2.1 \%)$.

\section{DISCUSSION}

This study showed that air pollutants were related to increasing outpatient and hospitalization rates of chronic respiratory diseases. $\mathrm{PM}_{2.5}, \mathrm{O}_{3}$, and $\mathrm{CO}$ had an acute effect on the risk of hospitalization, and $\mathrm{NO}_{2}$ was positively associated with an increased risk of outpatient visits for COPD. In asthma patients, $\mathrm{O}_{3}$, $\mathrm{SO}_{2}$, and $\mathrm{NO}_{2}$ were positively associated with an increased risk of outpatient asthma visits. These results were basically consistent with the results of previous studies. Each $10 \mu \mathrm{g} / \mathrm{m}^{3}$ increase in $\mathrm{PM}_{2.5}$ was associated with a $1.61 \%$ increase in the risk of hospitalization for patients with COPD in the United States and $0.82 \%$ in Beijing (5-6).

The present study showed that $\mathrm{CO}$ was positively associated with the risk of hospitalization in patients with COPD, which was inconsistent with the results of previous relevant studies. A few epidemiological studies have found that low levels of CO may have a protective effect in some cases. A time-series study in Hong Kong, China showed that short-term exposure to CO was associated with a reduced risk of hospitalization for COPD (7). However, in Spain, a retrospective study found that elevated CO levels were associated with increased hospital admissions in patients with COPD (8), which was the same as our results. Therefore, further studies are needed to confirm the direct health effects of $\mathrm{CO}$ exposure on patients with COPD. At the same time, our study shows that $\mathrm{PM}_{2.5}$ and $\mathrm{PM}_{10}$ were negatively associated with the risk of asthma outpatient visits, which was inconsistent with previous research results. A possible reason is that the concentrations of ozone and $\mathrm{PM}_{2.5}$ are seasonal and that asthma is affected by many factors. The overall confounders that could affect the association between pollutants and asthma exacerbations also need to be taken into 

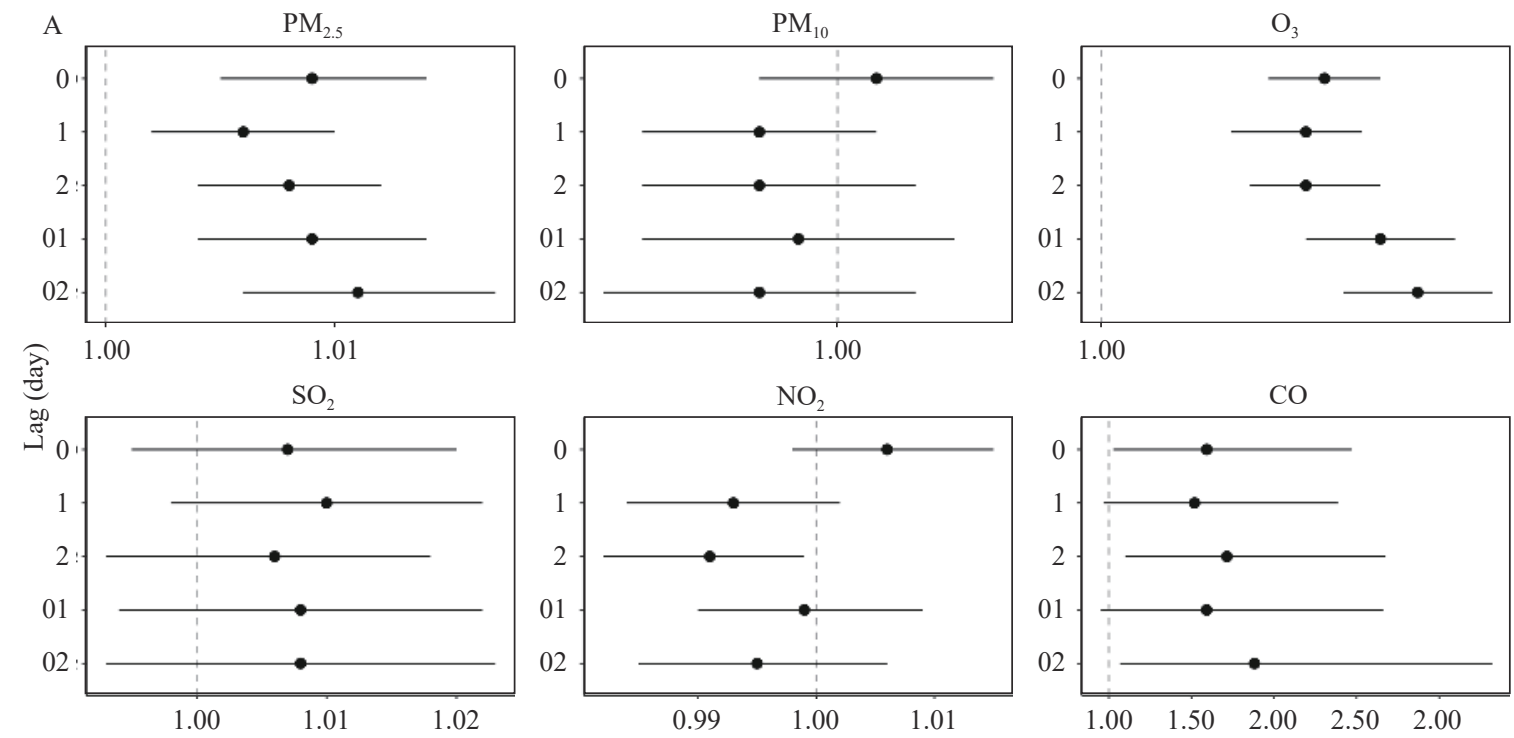

Relative risk for chronic obstructive pulmonary disease hospitalization per $10 \mu \mathrm{g} / \mathrm{m}^{3}$ increase in air pollution
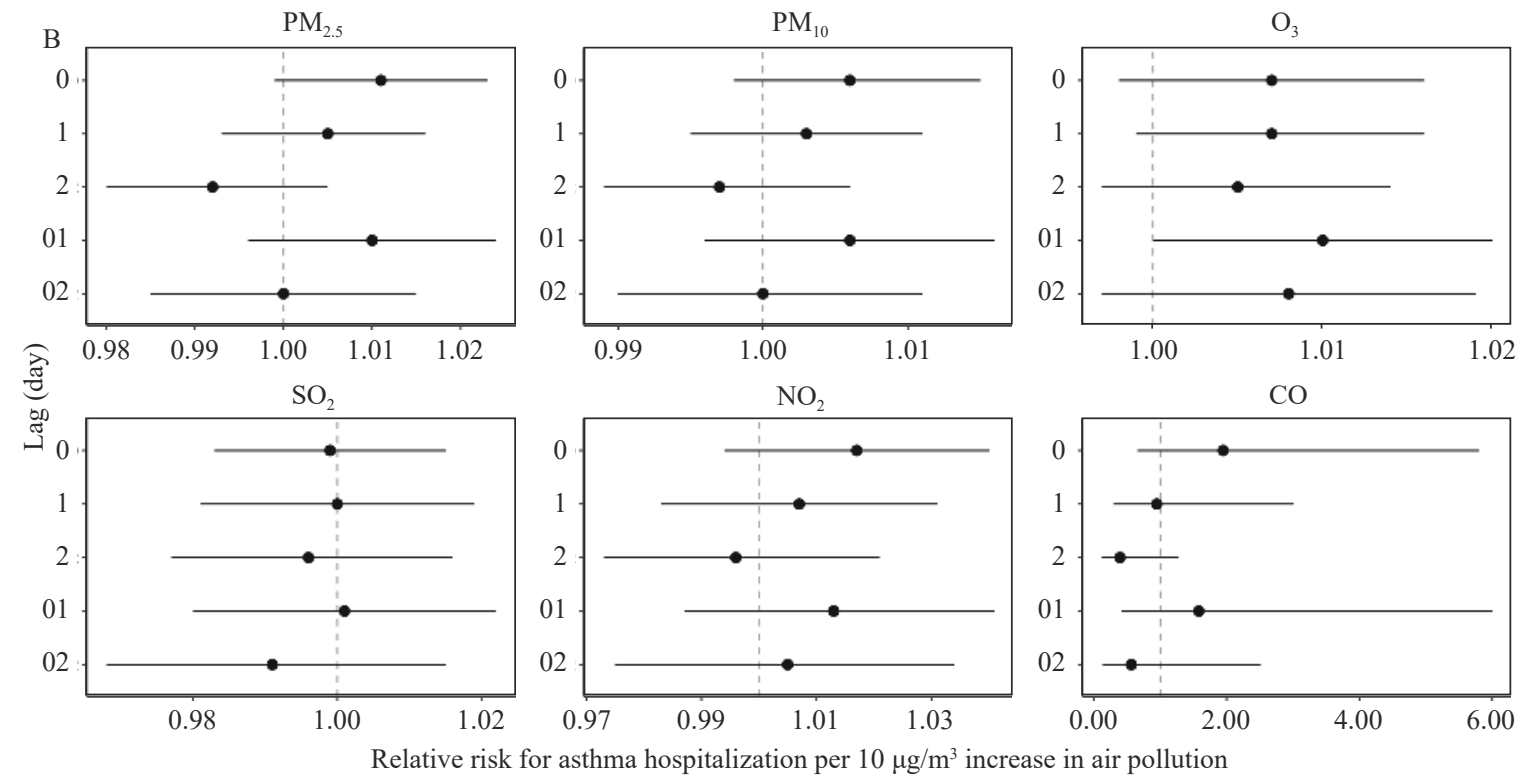

FIGURE 1. Relative risk for chronic obstructive pulmonary disease (A) and asthma (B) daily hospitalization per $10 \mu \mathrm{g} / \mathrm{m}^{3}$ increase in concentrations of air pollutants with different lag days in 16 hospitals, 2013-2018.

account and include meteorological factors and data for pollen.

The observed acute effects of particulate matters on respiratory diseases could be explained by inducing an imbalance of systemic inflammation, oxidative stress, autophagy, and apoptosis, and by affecting epigenetic modification. Studies showed that elevated level of blood biomarkers of systemic inflammation (e.g., IL-6, IL-8 and TNF- $\alpha$ ), coagulation (e.g., fibrinogen), soluble cluster of differentiation 40 ligands (sCD40L), soluble intercellular adhesion molecule-1 (sICAM-1), and fibrinogen, as well as DNA methylation levels were influenced by exposure to air pollutants (9-10).
This study was subject to some limitations. First, the acquisition of air pollution exposure data was from air monitoring stations, which might have some measurement errors. At the same time, the data of the monitoring station cannot fully represent the real exposure of patients, and there will be some exposure errors. Second, we did not obtain data on influenza, seasons and pollen, socioeconomic status, and daily activities, which may be some confounding factors related to outpatient visits and hospitalization. Third, we only analyzed the effects of one air pollutant on disease, but not the effects of exposure to multiple air pollutants. These deficiencies may make our results 

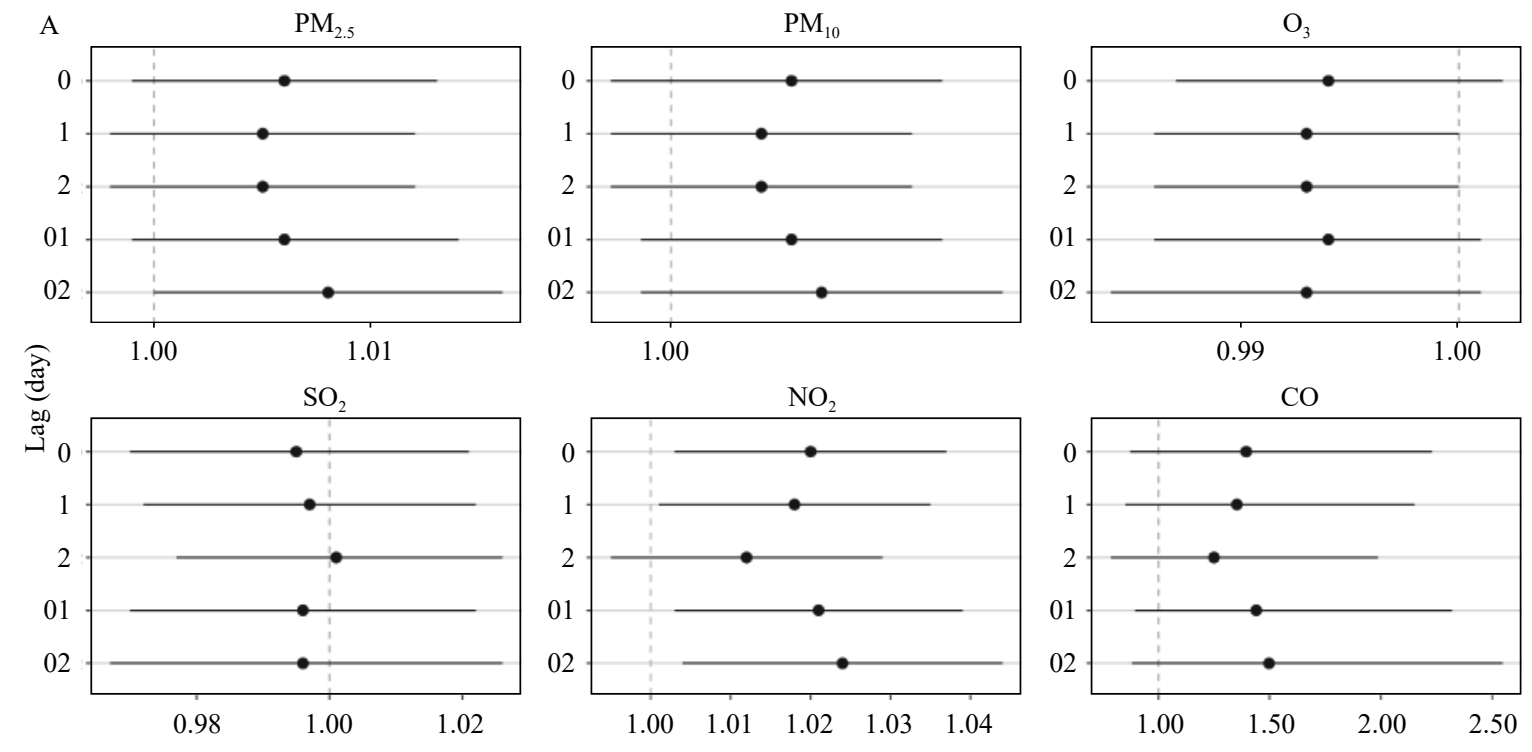

Relative risk for chronic obstructive pulmonary disease outpatient visit per $10 \mu \mathrm{g} / \mathrm{m}^{3}$ increase in air pollution
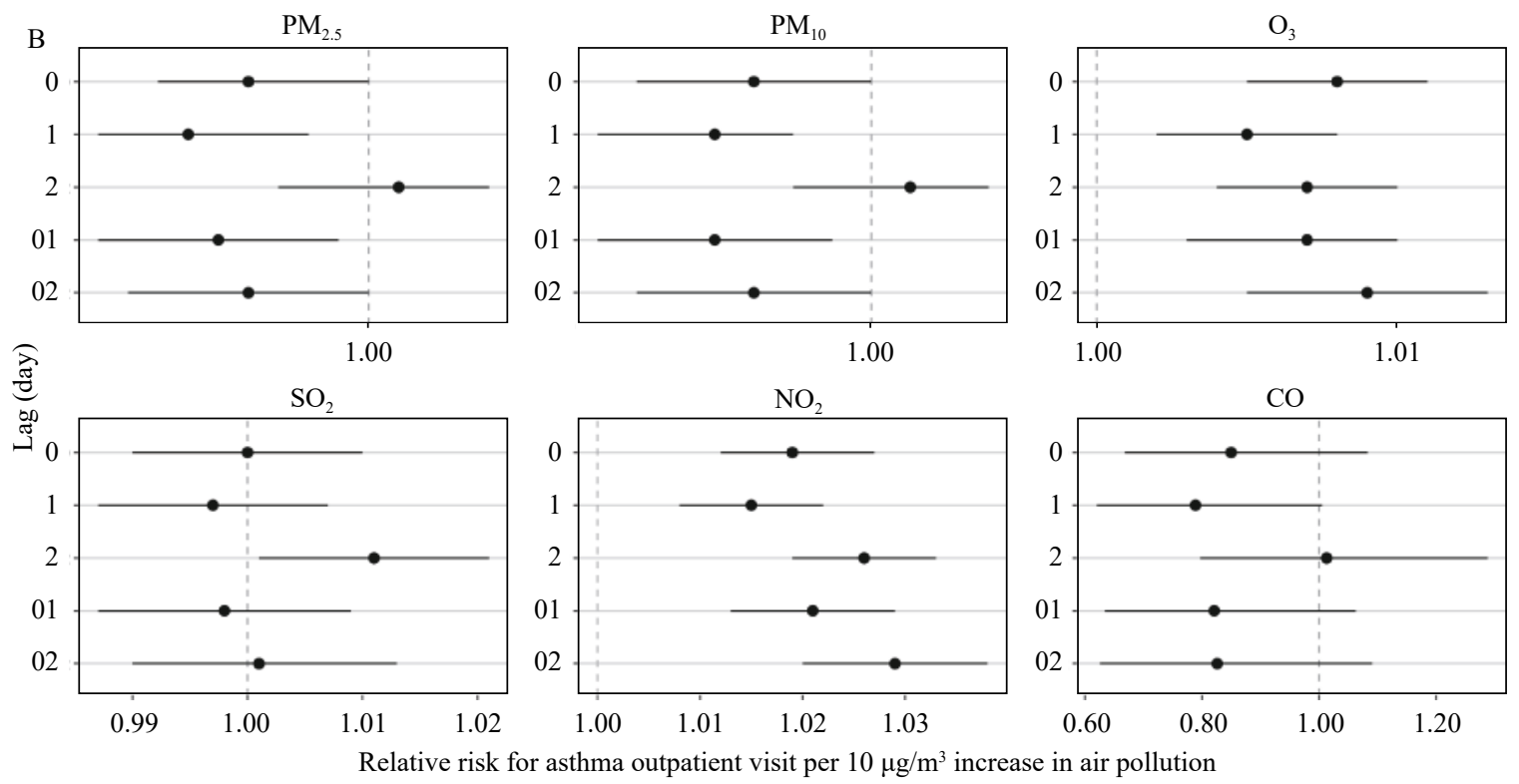

FIGURE 2. Relative risk for chronic obstructive pulmonary disease (A) and asthma (B) outpatient visits per $10 \mu g / \mathrm{m}^{3}$ increase in concentrations of air pollutants with different lag days in 16 hospitals, 2013-2018.

deviate to a certain extent, which needs further exploration.

In conclusion, exposure to $\mathrm{PM}_{2.5}, \mathrm{O}_{3}, \mathrm{SO}_{2}, \mathrm{NO}_{2}$, and $\mathrm{CO}$ has certain acute effects on outpatient and hospital admission of patients with COPD and asthma. Relevant susceptible people should try to reduce going out under the condition of air pollution to avoid aggravation of the disease. Meanwhile, these findings should be combined with disease diagnosis and treatment guidelines to guide clinical practice. This study not only paid attention to PM, but also emphasized that ozone cannot be ignored, which provides a reference for future research on the impact of PM and ozone coordinated prevention and control and on the effects of carbon neutralization on health.

Funding: The National Natural Science Foundation of China (81970043 and 91843302) and the CAMS Innovation Fund for Medical Sciences (CIFMS) (2020-I2M-2-009), and the National Research Program for Key Issues in Air Pollution Control (DQGG0402).

doi: $10.46234 / \mathrm{ccdcw} 2021.230$

\# Corresponding author: Ting Yang, zryyyangting@163.com.

${ }^{1}$ Department of Pulmonary and Critical Care Medicine, Center of Respiratory Medicine, China-Japan Friendship Hospital, Beijing, China; ${ }^{2}$ National Center for Respiratory Medicine, Beijing, China; 
${ }^{3}$ Institute of Respiratory Medicine, Chinese Academy of Medical Sciences, Beijing, China; ${ }^{4}$ National Clinical Research Center for Respiratory Diseases, Beijing, China; ${ }^{5}$ Peking Union Medical College, Chinese Academy of Medical Sciences, Beijing, China; ${ }^{6}$ Peking University China-Japan Friendship School of Clinical Medicine, Beijing, China; 7 BIC-ESAT and SKL-ESPC, College of Environmental Sciences and Engineering, Peking University, Beijing, China; ${ }^{8}$ Center for Environment and Health, Peking University, Beijing, China; ${ }^{9}$ Department of Pulmonary and Critical Care Medicine, The Second Hospital of Dalian Medical University, Dalian, Liaoning, China.

Submitted: October 26, 2021; Accepted: November 03, 2021

\section{REFERENCES}

1. Liu S, Jørgensen JT, Ljungman P, Pershagen G, Bellander T, Leander $\mathrm{K}$, et al. Long-term exposure to low-level air pollution and incidence of chronic obstructive pulmonary disease: the ELAPSE project. Environ Int 2021;146:106267. http://dx.doi.org/10.1016/j.envint.2020. 106267.

2. Doiron D, De Hoogh K, Probst-Hensch N, Fortier I, Cai YT, De Matteis S, et al. Air pollution, lung function and COPD: results from the population-based UK Biobank study. Eur Respir J 2019;54(1):1802140. http://dx.doi.org/10.1183/13993003.021402018.

3. Schikowski T, Adam M, Marcon A, Cai YT, Vierkötter A, Carsin AE, et al. Association of ambient air pollution with the prevalence and incidence of COPD. Eur Respir J 2014;44(3):614 - 26. http://dx.doi. org/10.1183/09031936.00132213.
4. Lu P, Zhang YM, Lin JT, Xia GX, Zhang WY, Knibbs LD, et al. Multi-city study on air pollution and hospital outpatient visits for asthma in China. Environ Pollut 2020;257:113638. http://dx.doi.org/ 10.1016/j.envpol.2019.113638.

5. Dominici F, Peng RD, Bell ML, Pham L, McDermott A, Zeger SL, et al. Fine particulate air pollution and hospital admission for cardiovascular and respiratory diseases. JAMA 2006;295(10):1127 - 34 . http://dx.doi.org/10.1001/jama.295.10.1127.

6. Gao NN, Li CH, Ji JD, Yang YL, Wang ST, Tian XL, et al. Short-term effects of ambient air pollution on chronic obstructive pulmonary disease admissions in Beijing, China (2013-2017). Int J Chron Obstruct Pulmon Dis 2019;14:297 - 309. http://dx.doi.org/10.2147/ copd.s188900.

7. Tian LW, Ho KF, Wang T, Qiu H, Pun VC, Chan CS, et al. Ambient carbon monoxide and the risk of hospitalization due to chronic obstructive pulmonary disease. Am J Epidemiol 2014;180(12):1159 67. http://dx.doi.org/10.1093/aje/kwu248.

8. De Miguel-Díez J, Hernández-Vázquez J, López-de-Andrés A, ÁlvaroMeca A, Hernández-Barrera V, Jiménez-García R. Analysis of environmental risk factors for chronic obstructive pulmonary disease exacerbation: a case-crossover study (2004-2013). PLoS One 2019;14(5):e0217143. http://dx.doi.org/10.1371/journal.pone.02171 43.

9. Lei XN, Chen RJ, Wang CC, Shi JJ, Zhao ZH, Li WH, et al. Personal fine particulate matter constituents, increased systemic inflammation, and the role of DNA hypomethylation. Environ Sci Technol 2019;53(16):9837 - 44. http://dx.doi.org/10.1021/acs.est.9b02305.

10. Chen X, Que CL, Yao Y, Han YQ, Zhang HXY, Li XY, et al. Susceptibility of individuals with lung dysfunction to systemic inflammation associated with ambient fine particle exposure: a panel study in Beijing. Sci Total Environ 2021;788:147760. http://dx.doi. org/10.1016/j.scitotenv.2021.147760. 